\title{
SILVA Y DURAND: DOS NOVELAS Y UNA SOLA FRONTERA NO MÁS
}

\author{
SILVA AND DURAND: TWO NOVELS \\ AND JUST ONE FRONTIER
}

\section{JAIME CONCHA*}

\section{RESUMEN}

El presente artículo estudia dos novelas chilenas de tema común, con diferentes cronologías. El tema común es la región de la Frontera en que se enfocan, al sur del Biobío, la llamada Araucanía; sus cronologías divergen doblemente, tanto por la ambientación de época (colonial en una, moderna en otra) como por las distintas corrientes narrativas en que se insertan. El mestizo Alejo y la criollita (1934-35) pertenece a un autor, Víctor Domingo Silva, que inició su carrera literaria al calor del nacionalismo y del populismo de comienzos del siglo pasado; Frontera (1949) es tal vez la obra principal de Luis Durand, segundo hombre del criollismo y brazo derecho del fundador, Mariano Latorre. A pesar de la disimilitud en forma y referentes, ambas novelas muestran la presencia y continuidad del problema indígena, que se arrastra desde la colonia, profundizándose durante la construcción republicana.

Palabras clave: Frontera, mestizo, criollo, indígena, mapuche.

\section{ABSTRACT}

This is a study of two Chilean novels with a common subject but different time settings. While both novels are centered on the Frontier, the so called Araucanía south of the Biobío River, they diverge in two aspects: first, their historical contexts (colonial and modern) and, second, the different literary narrative they are ascribed to. The work by

* Ensayista y crítico literario. Fue profesor en la Universidad de Concepción hasta 1973. En los Estados Unidos se desempeñó en la Universidad de Washington y en la Universidad de California, San Diego. Correo electrónico: jconcha@ucsd.edu 
V. D. Silva has nationalist and populist overtones, while Frontera, by Luis Durand, belongs to the "criollista" movement founded by Mariano Latorre. At any rate, these two narratives show clearly the persistence of the indigenous issue whose origin dates back to colonial times and which grew deeper during the creation of the republic.

Keywords: Frontier, "mestizo", "criollo", "mapuche”.

Recibido: 06.09.16. Aceptado: 24.10.16.

I

NTES DE ABORDAR EL TEMA concreto de este ensayo, me ha parecido
útil recordar algunas lecturas hechas a lo largo de mi vida profe-
sional y que tienen que ver con una cuestión tan compleja como la Frontera, ámbito común de las obras que comentaré. Ya cuando bregaba por elaborar una monografía sobre Neruda, tuve que adquirir información sobre la historia de la Frontera en el cambio de los siglos, del xix al $\mathrm{xx}$, para comprender mejor el ambiente que rodeó los orígenes del poeta. Además de la literatura secundaria, más bien dudosa, como las páginas de Francisco Encina en su Historia de Chile, pude acceder a fuentes de otro orden, algunas Memorias de Prueba que analizaban las escrituras de venta y cesión de tierras en pueblos y lugares de la región. Las páginas de Encina, vívidas sin duda, engrandecían el recuerdo de José Bunster, de un modo similar a la apologia del protagonista que veremos en Luis Durand -quien, de paso, conjura también el espectro glorioso de Bunster. No sé si hubo cruces entre ambos autores; la obra del novelista y el tomo correspondiente del historiador se escriben por el mismo tiempo, poco antes del mediosiglo. Las Tesis de Grado, por otra parte, especialmente la de Bernardo Arévalo, mostraban fehacientemente que la leyenda negra del robo de tierras, leyenda triangular, con vértices en el alcohol, en la ley y en la gran hacienda, no era en absoluto fabricación o hipérbole, sino pan de todos los días en la vida de la Frontera. El alcohol como arma contra el indígena (el "Jamaica" de que se habla constantemente en Frontera), los abogados, escribanos y tinterillos expertos en el despojo "legal" del aborigen, y el latifundista que se apoderaba de los nuevos terrenos, expropiando al indio y al colono a la vez, generando un creciente fenómeno de cuatrerismo, todos ellos obran y operan con la bendicion tácita de un Estado que no ve en tales prácticas usos o abusos desviados, sino la consecuencia natural de una misión intrínsecamente civilizadora. El sueño del Presidente Santa María es explícito y brutal: "No más salvajes en nuestro territorio" para que avance el tren, un 
tren que avanza con botellas y frascos de "Jamaica", con papel sellado firmado por analfabetos y el alambre de púa que deslinda pulcra y brutalmente la propiedad de la tierra (Concha, 1972, pp. 40-46, esp. nota 30). Tuve la suerte adicional -y me complace recordarlo- de trabajar en la biblioteca de la Universidad de Concepción en el mismo momento en que lo hacía Jacques Rossignol, profesor e historiador francés, afiliado a la Universidad por un convenio con el gobierno de su país, quien llevaba a cabo investigaciones sobre la inmigración en la Frontera, principalmente desde la provincia de Nuble. Es esta también la procedencia común y mayoritaria que se asigna al inmigrante en la obra de Durand (Rossignol, 2007). Y, a la vez, me fue dado leer uno de los grandes clásicos de la historiografia colonial, el libro de Alvaro Jara, Guerra y sociedad en Chile (1961), concebido con los criterios intelectuales y metodológicos que el autor había aprendido años atrás en Francia, al calor de los Annales, junto a Rugiero Romano en particular, pero que era asimismo un resultado del esfuerzo a que se había entregado Jara, junto a compañeros de Universidad (Rolando Mellafe, más que nadie; Sergio Villalobos en menor medida) al inicio de su profesorado para renovar nuestra anquilosada historiografía nacional, sobre todo la relativa al período colonial ${ }^{1}$. No era esto un mal comienzo para entrar en las cuestiones de la Frontera.

Mucho más tarde, al ingresar en los Estados Unidos, me di a la tarea de adentrarme, hasta donde me fuera posible, en la inmensa historia -absolutamente inabarcable, por cierto- de un país que es muchos países a la vez. Había leído con antelación, en castellano, una historia interpretativa, sintética, fuertemente crítica, del desarrollo norteamericano, por parte del historiador de Columbia, Richard Hofstadter ${ }^{2}$. Hombre de izquierda, que en su juventud había tenido simpatías y contactos marxistas en Buffalo y Nueva York, Hofstadter no dejó de ser objeto de molestias y presiones en medio del delirio macartista a inicios de la guerra fría. Murió relativamente joven (1916-1970), dejando una obra impresionante, de valor inestimable. Entre sus libros mayores figura The Progressive Historians (1968), que analiza tres figuras capitales de la historiografía estadounidense del siglo xx. La primera de ellas es justamente Frederick Jackson Turner, el historiador por antonomasia de la Frontera, que inaugura ese tipo de estudios con su obra magna sobre el avance hacia el Oeste, siguiendo la línea de los grandes

\footnotetext{
${ }^{1}$ Ver el interesante y esclarecedor Epistolario de Rolando Mellafe Rojas (a cargo de María Teresa González P.). Santiago: Ediciones del Centro Diego Barros Arana, 2006.

${ }^{2}$ Se trata de The American Political Tradition (1948), que leí en una traducción publicada en Barcelona en 1969.
}
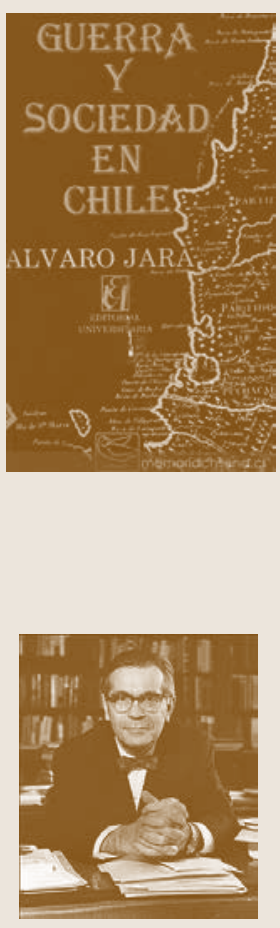

R. Hofstadter

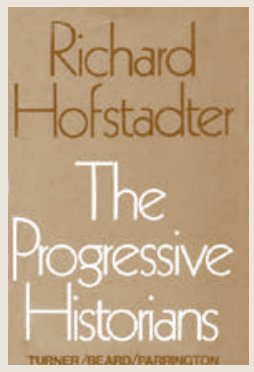


ríos en una marcha que se cierra muy cerca de 1898 -la fecha que Lenin fija para el origen del imperialismo contemporáneo. En efecto, la expansion imperial hacia el Caribe, hacia Hawaii, a las Filipinas, etc., era simplemente la continuación en ultramar de una Frontera continental que ya había llegado a su fin en la costa oeste del país -en los Estados de Washington, Oregon y California. Como siempre, la gran historiografía -igual que toda gran narrativa- es cosa póstuma, una vasta elegía a fuerzas colectivas que se dieron una vez, pero que ya no existen, pues son cosa del pasado, parte de un espacio definitivamente cerrado. Los artículos que Turner elabora entre 1893 y 1920, reunidos y publicados en ese último año, edifican el mito de una Frontera democrática, de un país pionero y dinámico, signado por el individualismo, que corta amarras con sus raíces europea y atlántica (las de Inglaterra y de Nueva Inglaterra), autocreándose en el empuje agrícola, comercial e industrial al compás de las grandes vías fluviales que jalonan el país. La figura del río, como membrana fronteriza por excelencia, preside la epopeya trazada por Turner, a la que veremos materializarse después en las imágenes cinematográficas de Ford y de Hawks. "The west looks to the future, the east toward the past", es la profecía de Turner en palabras de Hofstadter (cit., p. 63)

Fronteras históricas, entonces, las de la Nueva Araucanía y del Oeste norteamericano, que han dado paso en las últimas décadas a un cambio radical de perspectiva, que sitúa los estudios fronterizos bajo un paradigma francamente antropológico-culturalista, dirán otros. Es una nueva matriz conceptual, con nuevas agendas, nuevos programas de investigación y con un nuevo repertorio problemático. En gran medida ellos recogen y se hacen eco de los gigantescos fenómenos de diáspora y emigración que ocurren ante nuestros ojos, responden a la creciente rigidez en la política exterior de los países poderosos y reflejan la inevitable internacionalización de la situa-

\footnotetext{
${ }^{3}$ Mientras forjaba la imagen biológica de la membrana para aplicarla a la Frontera entendida más allá de una pura línea cartográfica, di con un trabajo que está en general fuera de mis luces científicas pero que anota esto con claridad: "Este concepto autónomo de frontera transciende el concepto usual de frontera porosa, usada (sic) en ciencias sociales, concepto que comparte un imaginario común con la biología de membranas celulares. El concepto de frontera de sí misma sitúa a la frontera en punto de enfoque central. La frontera no une o separa sistemas, es el sistema en sî" (v. Jesús Martínez Linares, "El concepto de frontera en la ciencia moderna", La Frontera: Una nueva concepción cultural. Actas del V Coloquio Inernacional (Raúl Sandoval, editor general), México, Universidad Autónoma de Baja California del Sur, 2003, pp. 229-232; la cita es de la pág. 232. Muy sugerente en sí misma, la idea corre el riesgo de diluirse hasta cubrir todo lo que sea contigüidad espacial. Si el espacio es, en su definición matemática, un conjunto infinito de puntos, ¡entonces la frontera resultaría ser un conjunto infinito de infinitos! Y esto es obviamente poco manejable.
} 
ción laboral, con la consiguiente interacción de grupos, familias y parejas más allá de su lengua y de sus propias culturas, etc. Todo ello es ahora foco preferido de la atención crítica. Giro teórico que puede seguirse muy bien, a veces de un modo cómico, en la mejor bibliografía especializada. Así, Roman Frontier Studies, revista para la cual la Limesforschung fue siempre un tema clásico y la niña de los ojos en la antiquística tardía, todavía discute en 1969 hasta el último detalle, arqueológica y filológicamente hablando, cada piedra de las murallas de Adriano o de Antonino; en 2004, uno de los más connotados especialistas ingleses en la disciplina da cabida en uno de sus libros a capítulos que prometen "Sex on the frontiers" $y$ "The use and abuse of immigrants in the Later Roman Empire" (cfr. Birley, Dobson, and Jarrett, 1974; Whittaker, 2004). De Tácito, con las fronteras obsesivas de su Agricola y su Germania (fronteras que Ercilla trasladará a su visión épica de la frontera araucana), pasamos bruscamente a la numismática y al análisis ultrafreudiano de bajorrelieves y esculturas. ¿Modernización, búsqueda desesperada en pos del "new look"? Renuévate o perecerás es sin duda, también aquí, la consigna impajaritable.

El dúo narrativo de que voy a hablar resulta de simples circunstancias personales. Cuando empezaba a interesarme por las obras de imaginación (lo que después sabría que se llamaba "literatura"), tuve ocasión de oír, en una ciudad del sur, una pieza de radioteatro transmitida desde la capital. Gracias a las inolvidables voces de Mireya Latorre, de Emilio Gaete y, tal vez, de Silvia Infanta, nos llegaba a través de la noche la historia de El mestizo Alejo y la criollita, que recibíamos en torno a un brasero -como deben escucharse las novelas verdaderas, según Stendhal. Una vieja historia colonial se difundía así a lo largo de todo el país. Frontera (1949) la leí cuando estaba aún en el liceo; y, amén de los perturbadores ecos eróticos que no dejaba de suscitar (ahora veo que no eran tantos como los que creía recordar), me hizo reflexionar, con la imprecisión con que se piensa a esa edad, en la ambigua proyección de su personaje principal. Hombre de ley y situado casi siempre del lado del bien (morirá atacado por una banda de forajidos), Anselmo Mendoza me impedía toda identificación con él, no me atraía para nada; mis preferencias iban más bien hacia bandidos y ladrones -los mismos que en el cine de esos años llenaban la pantalla de suspenso y de ansiedad. Uno estaba por ellos, eran ellos los que despertaban nuestra simpatía y solidari-
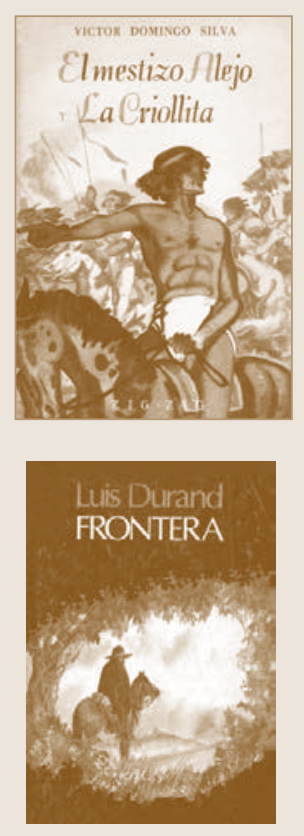


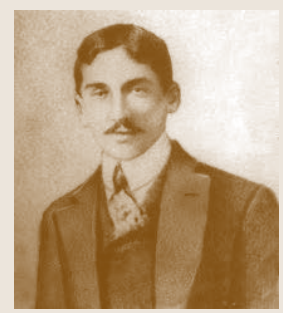

V. D. Silva

dad, no los representantes de las fuerzas del Estado. ¿Habrá en todo lector, me pregunto, un anarquista virtual?

Empiezo ya con Silva y su novela. A pesar de recibir el Premio Nacional de Literatura en 1954, es claro que Víctor Domingo Silva (1882-1960) no se cuenta entre los autores predilectos de hoy. Acaso ello derive de razones estéticas, desde luego, y del hecho indudable de que sus preocupaciones ya no corresponden a las nuestras. Su vida de escritor transcurre en más de medio siglo de nutrida actividad cultural en el país, entre 1905, fecha de su primer libro (los poemas de Hacia allá...), y 1960 , año de su muerte. Cultivó prácticamente todos los géneros, dejando una obra amplia y variada de la cual, sin embargo, solo habría que retener en rigor un escaso puñado de poemas y un haz de novelas regido por una ideología populista y nacionalista que se acentuará en los años treinta. Varios de sus personajes descienden de $E l$ roto (1920), de Edwards Bello, y aunque más optimistas y a veces picarescos, carecen del tono trágico de éste. Diversa, por su carácter y ambientación, resulta ser El mestizo Alejo y la criollita, publicada en dos partes sucesivas $(1934,1935)$ y objeto de no pocas reediciones posteriores.

Novela semihistórica basada en un asunto que tuvo lugar a mediados del siglo xvii en la zona del Bío-Bío, ella relata la meteórica aventura militar de un mestizo que se pasa al bando de los indios y que por cerca de tres años lleva a cabo una guerra victoriosa contra el poder español. A esta base factual, probablemente recogida en páginas de Barros Arana (1999, pp. 14-23), el autor agrega una historia de amor, de gran vigor melodramático que haría las delicias de numerosos radio-oyentes. En un país sin Scott, en que el género de la leyenda nacional casi nunca ha cuajado a fondo, este es uno de los pocos especímenes con que contamos de auténtica novela histórica ${ }^{4}$. (El ejemplo mayor sigue siendo, sin disputa, Durante la reconquista [1897] de Blest Gana). "La maravillosa vida del primer toqui chileno" reza el subtítulo de la obra, que se suma así a las muchas manifestaciones de lo que también Edwards Bello denominaría acertadamente "nacionalismo continental". La novela, escrita al parecer en su totalidad en España, durante las funciones consulares del autor, lleva una dedicatoria a D. Alonso de

\footnotetext{
${ }^{4}$ Por los mismos años en que sale a luz la novela de Silva, se reeditan algunas leyendas nacionales de Liborio Brieba, sobre todo un trío relativo a la Independencia: La San Bartolomé de los patriotas (1933), que se liga explícitamente a Los Talaveras y a El capitán San Bruno. El clima nacionalista, se lo ve, es muy marcado. Otra cosa son las Narraciones históricas (1876) de Miguel Luis Amunátegui, elaboradas con mayor consciencia historiográfica y más afines quizás a las Tradiciones peruanas de Ricardo Palma, aunque sin el gracejo y la "sal ática" (!) de este -como habría dicho sin duda el inefable don Marcelino...
} 
Ercilla y Zúñiga, muy presente en su visión configuradora y a veces citado explícitamente en la narración. De hecho, Alejo lee el texto de La Araucana, se lee a sí mismo como continuador de la epopeya ercillana. Este ángulo será factor importante en la perspectiva ideológica que diseña el novelista. El poeta español, por las características conocidas de su obra, parece servir de puente de unión entre el mestizaje y la criollidad propugnados por Silva. Prueba al canto de esto último podría ser el hecho de que Silva, hombre del norte a la postre (nació en Tongoy, localidad del Norte Chico), emplee sus años europeos persiguiendo la historia de Orélie-Antonie, el rey de la Araucanía. Es decir, al mismo tiempo que trabaja en su novela colonial, está investigando sobre la Frontera moderna, la cual no dejó de acuciar el apetito de un aventurero del Segundo Imperio ${ }^{5}$.

La novela está compuesta con una rara y extrema simetría: veinte capítulos para la primera parte, la de "El mestizo Alejo", veinte también para la segunda, de "La criollita". A la primera precede un "Prólogo", a la segunda sigue un "Epílogo". Esta estructura es ambigua, sin embargo. Como los dos hemisferios que forman la obra de Garcilaso, uno para el mundo incaico, otro para la conquista española, las dos mitades narrativas separan y unen a la vez. Separan: el mestizo encabeza una lucha que va contra el mundo de su madre y de su amada, las dos criollas; pero unen también: el mestizo muerto persistirá en la criollidad de María Francisca, que se hará cargo de sus esposas indias y de su hijo mapuche. En cuanto reconstrucción histórica, la novela cumple bien su papel de describir las formas de la sociedad colonial y las costumbres mapuche, los contornos de la villa y del campamento, las jerarquías civil y eclesiástica con sus ritos y celebraciones, las iniciativas de las cofradías, etc. y la contraposición de creencias entre los dos bandos en juego. La descripción de un nguillatún, por ejemplo, no desmerece en nada lo que después conoceremos a través de páginas clásicas de Alfred Métraux sobre el chamanismo araucano. Hay una clara voluntad de equilibrio al tratar de las fuerzas en pugna. Por un lado, del lado español, valores de dignidad, de señorío, de orgullo, de obediencia ciega al rango y a las precedencias; por el otro, el coraje araucano, la capacidad de sus jefes, la entrega a la lucha en defensa de la tierra, etc. La crueldad es compartida por ambos bandos y los defectos comunes a ambos grupos son más bien los del exceso. La causa que se asigna a la decisión de Alejo de optar por sus antepasados paternos es la del desprecio a que lo someten sus compañeros

${ }^{5}$ Ver El rey de la Araucanía. Andanzas y malandanzas de S.M. Orélie Antoine, Zig-Zag, s.f. 1936 ? Se trata de una biografía novelada de escaso valor.

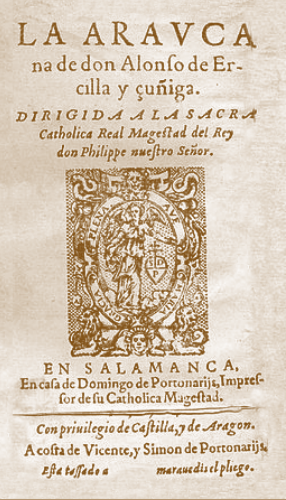

LA ARA V C A de don Alonfo de Er GID A I A SACRA don Philippe nueftro Serior. (2) 5 ?

is

1) 121 Encafade Domingo de Porronarijist Tmpref-

Con privilegio de Caffilla, 7 de Aragon. Efateffidos. 
de milicia ("guacho" es un insulto que se pronuncia desde el inicio de la novela, con un cierto anacronismo, me parece; cf. pp. 208, 273, 306 passim) y la injusticia con que se desconocen sus méritos militares. Es la misma, entonces, que ventilarían los criollos un siglo después durante el Dieciocho y la preindependencia contra los privilegios peninsulares. Una vez más, lo mestizo y lo criollo se amalgaman con vistas a la nueva nacionalidad.

La simetría y el equilibrio de la novela no solo se imponen en lo estético y formal, sino también en el marco ideológico. En el primer aspecto, lo solemne y lo jocoso coexisten en la interacción de personajes como María Francisca, con su histérica pasión barroca que induce en ella una miseria psíquica y corporal, y el joven criado de Alejo, Juan Yuyo o Yuyito; es un rasgo típico del melodrama. En lo segundo, las tensiones internas del mapa ideológico son sometidas a un riguroso control, siendo tal vez el elemento negro y el principio femenino los agentes de mayor desestabilización.

Igual que en La Araucana, el racismo bloqueado por la admiración ante el indio halla un cauce alternativo en la visión peyorativa del negro. Allí era verdugo, acá es cruel "capataz de minas". Sin embargo, de modo bien ambiguo, uno de los pocos combates singulares de relieve que hay en la novela es el que protagonizan Alejo y el negro Pachingo, cuya fuerza y valentía se presentan como excepcionales, hasta el punto de vérselo como un "hércules negro" (cf. p. 151; tb. p. 148). El duelo forma trío con el combate del Prólogo contra un "centauro" indio y el que se lleva a cabo con Zúniga, un viejo capitán español, inveterado enemigo de Alejo.

Por su parte, la madre, al negociar con su hijo para que no ataque a la Concepción, crea una unión por encima de la misma frontera fluvial que divide los bandos. María Francisca, como hemos dicho, recoge el legado del mestizo asesinado por sus familiares indios. Y Papay, la nodriza india que cruza casi toda la novela integrando los polos emocionales de la historia, se alza al plano de figura extraordinaria por su astucia, amor y saber. La salvación de la joven criolla, basada en la medicina araucana y sentida como un milagro por la gente cristiana, echa luz oblicua y aguda sobre las creencias alternantes. Todas estas mujeres: madre, novia, nodriza, convergen en un signo de fusión, que apunta prospectivamente a la nacionalidad ulterior.

Por último, las tensiones internas existentes en el mundo indígena son también de gran interés. Los mapuche se sitúan en medio de los puelches, caricaturizados en el episodio del chapucero cacique don Bartolo, y de los tehuelches, vistos como salvajes por la destrucción que llevan a cabo de la misión del padre Rogelio, un abnegado franciscano que fue maestro de Alejo en su niñez. En cambio, la alianza entre mapuches y los pehuenches 
cordilleranos, encabezados por el cacique Inaqueupen (también figura histórica y, para decirlo con un doble anacronismo, especie de Tupac Catari que representaría el ala radical de la resistencia indígena), muestra el alcance de la gran estrategia araucana al combinar las tácticas de la montonera y la guerrilla junto a un minucioso proceso de elaboración de armas de fuego. Por otra parte, los mitayos son vistos como carne servilizada, aptos para la delación y la traición. Sobre este mundo indio se ciernen siempre las sombras de la borrachera y de la superstición -sus adversarios íntimos más letales en la percepción del autor.

Y una breve nota final respecto a la "geograficidad" inherente a la novela, punto sobre el cual no puedo extenderme. Básicamente, la entiendo como equivalente a la historicidad. Así como esta supone la historia como serie de hechos y acontecimientos del pasado y una historiografía que se ejerce sobre ella mediante escritos y la forma discursiva, la "geograficidad" es el sentido y sensibilidad de la tierra en que se habita, distintos de la ciencia geográfica, con sus mapas y sus fronteras nacionales y regionales, etc. Apunta, en esencia, a nuestra condición terrestre, local, concreta y planetaria a la vez. Desde el inicio mismo del relato, que se abre con "las Tetas del Bío-Bío" ("cruda expresión de geografía náutica", se disculpa púdicamente el narrador ${ }^{6}$ hasta la intensa inmersión en la cuenca del Laja -tierra ancestral, cuna del linaje y de los antepasados de Alejo- la novela transmite y hace sentir una forma de radicación en el mapu como ámbito de vida y de vivencia colectiva. A veces, curiosamente, se une a ella un sentimiento franciscano de la naturaleza, vehiculado por el padre Rogelio (p. 19). Este ánimo culmina tanto en la fusión de plantas autóctonas y flores de origen europeo (pp. 89-90 y 141) como, muy significativamente, en la experiencia del terremoto que ocurre por esos años (Segunda Parte, cap. III, ab initio, p. 289). Utopía floral y caos geológico son dos caras de las fuerzas raigales y centrífugas que conviven en la novela y en la tierra de sus habitantes. Son manifestación y figuras de hibridación.

III

Si El mestizo es de asunto colonial, Frontera nos introduce en plena época moderna, a fines del siglo xix, en un contexto nacional determinado doble-

\footnotetext{
${ }^{6}$ Estoy usando la edición Zig-Zag, sin fecha, 514 pp. + un apéndice con "Voces de procedencia indígena”. La original: 1934, 227 pp.; 1935, 251 pp.
} 
mente por las consecuencias de la guerra del salitre y la reciente ocupación de la Araucanía. Ambas se tocan. Cuando se inicia la novela, vemos todavía a soldados y oficiales de la campaña del Perú actuando en la región. El famoso "héroe" de Huamachuco, de nombre epónimo pues así se lo llama popularmente, está allí en el reparto de caracteres. Se inicia de este modo un hábil entrelazamiento entre el norte y el sur que continuará desenvolviéndose a lo largo de la obra ${ }^{7}$.

La novela es de estructura lineal y de composición tradicional. Los capítulos se organizan en general en torno a acontecimientos bien definidos: la visita de Anselmo a su madre enferma; un baile de despedida al coronel de la guarnición; un accidentado viaje en coche por el interior de la región, etc., permiten dar una visión densa y variada de la vida en la zona, en sus aspectos ambientales y humanos, con una rica gama étnica de blancos y mapuches, franceses, ingleses, etc. Pero a diferencia de la arquitectura límpidamente simétrica que observábamos en Silva, Frontera manifiesta una marcada desproporción entre su primera y segunda parte. Los 16 capítulos de una (271 pp.) concentran una acción que ocupa apenas unos pocos meses, al hilo de la consolidación de los negocios de Anselmo y de su noviazgo y matrimonio con Isabel; los escasos 9 capítulos de la otra parte (pp. 277375) abarcan en menos de cien páginas cinco años, a partir de la muerte de Isabel y de la revolución del 91 en que el personaje participa sin mucha convicción. Desproporción cronológica, por tanto, y desigualdad temática, que podrían sugerir que los sucesos del '91 ejercen un impacto profundo en el mundo narrado. Un Anselmo distinto, sin ánimo, totalmente desorientado muere sin lógica alguna hacia el fin del relato. La novela pareciera conllevar dos cargas, dos signos contrapuestos: una carga positiva, de empuje y dinamismo, en que la esperanza familiar y la económica se conjugan, da paso a una atmósfera de desilusión, de ruina humana y colectiva. Ni aun el amorío final de Anselmo con Emilia enciende realmente una nueva chispa en una vida pasiva, que se apaga y se extingue sin más. Evidentemente el '91 establece un corte histórico que el escritor no quiso, no pudo o no supo manejar. Otra hipótesis sería que se buscara destacar justamente la ausencia del Estado nacional, su distancia y a la vez gravitación desde lejos sobre el mundo de la Frontera. La presencia esporádica de un político en el prostíbulo del pueblo podría leerse tal vez en ese sentido. Sea lo que fuere,

\footnotetext{
${ }^{7}$ Donald M. Decker describe la larga gestación de la novela, su base biográfica en la infancia del autor y menciona el primer título en que pensó Durand, el de Tierra virgen (Decker, 1971, p. 135).
} 
la novela detecta una fisura, que no es solo un dato textual, sino que apunta al referente cronológico y a su horizonte contextual. Toda una época, toda una historia, parecieran dejar allí una huella de oquedad.

Por último, importa hacer notar que el cuatrerismo omnipresente, por un lado, y la corrupción de los jueces, por otro, muestran que el problema principal en ese tiempo y en la región es el problema de la ley. Esto asemeja Frontera a las novelas de la tierra de décadas atrás, especialmente La vorágine (1924) y Canaima (1935), donde eso mismo es central. Es la falta de la ley, tanto por el dominio feudal de la vendetta como en la falta de la Justicia propiamente tal (el juez representa en Durand la suprema manifestacion de la injusticia), lo que caracteriza el universo moral y político de la Frontera. Al fin de la novela, mientras el tren triunfa, la ilegalidad sigue rampante. Progreso técnico y primitivismo en el crimen y el delito coinciden plenamente.

\section{IV}

En suma, la frontera es en principio un lugar de encuentro y desencuentros. Estos últimos son casi siempre conflictivos, llegando a veces a la abierta hostilidad; aquél suele verse a menudo, sobre todo por una historiografía que tiende a acentuar el hibridismo o la fusión, como matriz y gestación de una nueva comunidad.

Dos textos "fronterizos": una novela semihistórica de los años treinta y un bestseller criollista de mediados de siglo ficcionalizan, respectivamente, hechos ocurridos en el Diecisiete al sur del Biobío y la vida de un pionero moderno en una Araucanía ya "pacificada" entre Angol y Traiguén. Aunque en la obra de Durand hay apología y mitificación del colono, no hay únicamente eso.

Dos épocas, dos espacios. $\mathrm{Y}$, sin embargo, la continuidad territorial e histórica no deja de ser evidente, imbricando dos textos tan diversos en forma e intención, como fases de un mismo proceso de dominación ininterrumpida. De la "criollita" de uno al "criollismo" del otro hay solo un paso.

\section{REFERENCIAS}

Amunátegui, M. L. (1876). Narraciones históricas. Santiago: Imprenta Nacional.
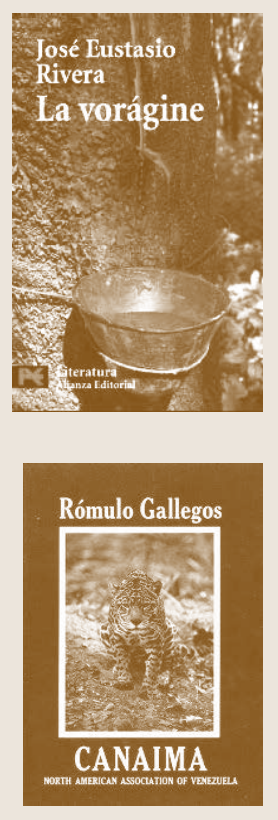
Barros Arana, D. (1999). Historia general de Chile, tomo V. Santiago: Editorial Universitaria.

Birley, E.; Dobson, B.; and Jarrett, M. (1974). Roman Frontier Studies 1969. Cardiff: University of Wales Press.

Blest Gana, A. (1897). Durante la reconquista. París: Garnier Hermanos.

Brieba, L. (1933). La San Bartolomé de los patriotas. Santiago: Ercilla. . (1936 [1871]). Los Talaveras. Santiago: Ercilla. . (1946 [1875]). El capitán San Bruno. Santiago: Zig-Zag.

Concha, J. (1972). Neruda (1904-1936). Santiago: Editorial Universitaria.

Decker, D. M. (1971). Luis Durand. New York: Twayne Publishers.

Durand, L. (1949). Frontera. Santiago: Nascimento.

Edwards Bello, J. (1927 [1920]). El roto. Santiago: Nascimento.

Ercilla, A. de (1993 [1574-1589]). La Araucana. Madrid: Cátedra.

Gallegos, R. (1935). Canaima. Barcelona: Araluce.

González P., M. T. (Ed.) (2006). Epistolario de Rolando Mellafe Rojas. Santiago: Ediciones del Centro Diego Barros Arana.

Hofstadter, R. (1948). The American Political Tradition and The Men who made It. New York: Vintage Books.

Hofstadter, R. (1969). La tradición política americana y los hombres que la forjaron. Barcelona: Seix Barral. ( $1^{\text {a }}$ edic., The American Political Tradition and The Men who made It. New York: Vintage Books, 1948).

Jara, A. (1971). Guerra y sociedad en Chile. Santiago: Editorial Universitaria. (1ª Ed. en francés, Guerre et Societé au Chili, Université de Paris, 1961).

Martínez Linares, J. (2003). "El concepto de frontera en la ciencia moderna”. En Sandoval, R. (Ed.), La Frontera: Una nueva concepción cultural. Actas del V Coloquio Inernacional (pp. 229-232). México: Universidad Autónoma de Baja California del Sur.

Palma, R. (1893). Tradiciones peruanas. Barcelona: Montaner y Simón.

Rivera, J. E. (1924). La vorágine. Bogotá: Cromos.

Rossignol, J. (2007). Chilenos y mapuches a mediados del siglo xix: una situación colonial: estudios históricos. Compilación de Raúl Guerrero. Concepción: Ediciones Universidad del Bío-Bío.

Silva, V. D. (1905). Hacia allá... Santiago: Impr. i Encuadernación Universitaria.

. (1934-1935). El mestizo Alejo y la criollita. Santiago: Zig-Zag. . (1936?). El rey de la Araucanía. Andanzas y malandanzas de S.M. Orélie Antoine. Santiago: Zig-Zag.

Whittaker, C. R. (2004). Rome and its Frontiers: The Dynamics of Empire. London: Routledge. 